Folia Cardiologica 2021

\title{
Relationship between atrial fibrillation and retinal artery occlusion: what we know now and how we can use it in clinical practice?
}

\author{
Joanna Roskal-Wałek ${ }^{1,2}$ (D), Paweł Wałek ${ }^{1,3}$, Jacek Sidło², \\ Jan Biskup ${ }^{4}$, Jerzy Mackiewicz ${ }^{5}$, Beata Wożakowska-Kapłon ${ }^{1,3}$ \\ ${ }^{1}$ Collegium Medicum, The Jan Kochanowski University, Kielce, Poland \\ ${ }^{2}$ Ophthalmology Clinic, Voivodeship Regional Hospital, Kielce, Poland \\ ${ }^{3} 1^{\text {st }}$ Clinic of Cardiology and Electrotherapy, Swietokrzyskie Cardiology Center, Kielce, Poland \\ ${ }^{4}$ Voivodeship Regional Hospital, Kielce, Poland \\ ${ }^{5}$ Department of Vitreoretinal Surgery, Medical University of Lublin, Lublin, Poland
}

\begin{abstract}
Atrial fibrillation (AF) is the most common heart rhythm disorder that constitutes the cause of ischemic stroke. Retinal artery occlusion (RAO), believed to be the equivalent of ischaemic stroke, is one of the causes of sudden vision loss that is related to an increased risk of cardiovascular events. The relationship between AF and ischaemic stroke is well known. Gaining knowledge about the relationship between AF and RAO seems essential. Is the presence of AF associated with the risk of RAO? What impact does RAO have on the prognosis of patients with AF? Should patients with RAO be examined for AF? What treatment should be introduced in RAO patients recently diagnosed with AF? Knowing the answers to these questions appears to be essential in daily clinical practice. A literature review on the relationship between $\mathrm{RAO}$ and $\mathrm{AF}$ is presented.
\end{abstract}

Key words: atrial fibrillation, retinal artery occlusion, ischemic stroke

Folia Cardiologica 2021; 16, 5: 311-317

\section{Introduction}

Atrial fibrillation (AF) is the most common supraventricular arrhythmia, that affects $1.0-1.5 \%$ of the general population. It is estimated that 400,000 people in Poland suffer from this disease [1]. It is the most common cardiac arrhythmia that causes ischaemic stroke [1, 2]. Approximately one-third of all strokes are caused by AF. These strokes are associated with a worse prognosis, higher mortality and higher disability rates than ischaemic strokes in patients with arrhythmia. In many cases, stroke is the first clinical manifestation of AF [2]. The risk of AF-related stroke increases from 1.5\% per year in the sixth decade of life to $24 \%$ per year in the ninth decade of life [3].

Retinal artery occlusion (RAO) is one of the causes of acute retinal ischemia. It is an emergency condition that requires urgent diagnostic evaluation and treatment [4]. Based on the vessel affected, one can divide RAO into central retinal artery occlusion (CRAO) and branch retinal artery occlusion (BRAO). Both CRAO and BRAO are equivalent to stroke $[4,5]$. Despite the low incidence of RAO, CRAO (incidence rate $=1.64$ per 100,000 person-years) and BRAO (incidence rate $=4.99$ per 100,000 person-years) [6], the occurrence of this episode has very important clinical

Address for correspondence: Joanna Roskal-Wałek MD, PhD, Klinika Okulistyki, Wojewódzki Szpital Zespolony, ul. Grunwaldzka 45, 25-736 Kielce, Poland, phone +48 4136714 40, fax +48 4136715 10, e-mail: joanna.roskal.walek@wp.pl

This article is available in open access under Creative Common Attribution-Non-Commercial-No Derivatives 4.0 International (CC BY-NC-ND 4.0) license, allowing to download articles and share them with others as long as they credit the authors and the publisher, but without permission to change them in any way or use them commercially. 
Table 1. Components of the $\mathrm{CHA}_{2} \mathrm{DS}_{2}$-VASc scale

\begin{tabular}{|c|c|c|c|}
\hline & $\begin{array}{l}\text { Risk factors and defi- } \\
\text { nition }\end{array}$ & Points & Definition \\
\hline C & $\begin{array}{l}\text { Congestive HF, clinical } \\
\text { HF, moderate or severe } \\
\text { LV dysfunction or HCM }\end{array}$ & 1 & $\begin{array}{l}\text { Recent decompensated HF, irrespective of LVEF (HFrEF or HFpEF), or presence of moder- } \\
\text { ate or severe LV systolic function impairment (also asymptomatic) in cardiac imaging }\end{array}$ \\
\hline H & Hypertension & 1 & $\begin{array}{l}\text { Resting blood pressure }>140 / 90 \mathrm{~mm} \mathrm{Hg} \geq 2 \text { measurements taken on different occa- } \\
\text { sions or appropriate hypotensive treatment }\end{array}$ \\
\hline $\mathrm{A}_{2}$ & Age $\geq 75$ years & 2 & \\
\hline \multirow[t]{3}{*}{ D } & \multirow[t]{3}{*}{ Diabetes } & \multirow[t]{3}{*}{1} & 1) Random venous blood glucose $\geq 200 \mathrm{mg} / \mathrm{dl}(\geq 11.1 \mathrm{mmol} / \mathrm{L})+$ symptoms of diabetes \\
\hline & & & 2) Double measurement of fasting blood glucose $\geq 126 \mathrm{mg} / \mathrm{dL}$ ( $\geq 7 \mathrm{mmol} / \mathrm{L}$ ) \\
\hline & & & 3) $0 \mathrm{GTT} \geq 200 \mathrm{mg} / \mathrm{dL}$ ( $\geq 11.1 \mathrm{mmol} / \mathrm{L}$ ) \\
\hline $\mathrm{S}_{2}$ & $\begin{array}{l}\text { History of stroke/TIA/ } \\
\text { /thromboembolic event }\end{array}$ & 2 & History of stroke, TIA or peripheral embolism (including RAO*) \\
\hline V & Vascular disease & 1 & $\begin{array}{l}\text { History of myocardial infarction, atherosclerotic peripheral artery disease, atherosclerotic } \\
\text { plaque in the aorta }\end{array}$ \\
\hline A & Age $65-74$ & 1 & \\
\hline Sc & Female & 1 & Increases the risk if $\geq 1$ other risk factor is present \\
\hline Max & m score & 9 & \\
\hline
\end{tabular}

*According to the definition adopted by American Heart Association (AHA) and American Stroke Association (ASA) [5]; HF - heart failure; LV - left ventricle; HCM - hypertrophic cardiomyopathy; LVEF - left ventricular ejection fraction; $\mathrm{HFrEF}$ - heart failure with reduced ejection fraction; $\mathrm{HFpEF}$ - heart failure with preserved ejection fraction; HFpEF - heart failure with preserved ejection fraction; $\mathrm{HFpEF}$ - heart failure with preserved ejection fraction; OGTT - oral glucose tolerance test; TIA - transient ischemic attack; RAO - retinal arterial occlusion

implications, also concerning AF [4, 7]. If RAO is equivalent to stroke, it is necessary to undertake strictly defined diagnostic and treatment actions, analogous to those implemented after an episode of acute cerebral ischaemia with prompt neuroimaging and cardiovascular control. It is currently recommended that, like stroke patients, patients with acute CRAO or BRAO should be referred for urgent diagnostic evaluation at the nearest stroke centre or a hospital emergency department at which it is possible to conduct such a diagnostic evaluation [4].

Most commonly, RAO is a consequence of an embolism originating from atherosclerotic plaques in the ipsilateral carotid artery, heart, or aortic arch $[4,8]$. Recently, the role of cardiac arrhythmias in the aetiology of RAO has also been receiving increasing attention [9-16]. Results of previous studies concerning the relationship between $\mathrm{RAO}$ and $\mathrm{AF}$ indicate that there is a correlation between $A F$ and RAO. RAO episodes were more frequently observed in the AF group, and RAO patients were more frequently diagnosed with AF compared with control groups [9-12]. A higher rate of rehospitalization of RAO patients compared with ischemic stroke patients due to cardiac arrhythmias including AF is also noteworthy, indicating the necessity to conduct a mandatory diagnostic evaluation in this group of patients for AF [16], especially given the fact that RAO patients are at a high risk of stroke in the period immediately following RAO [6, 16-20]. Available data indicate that in the case of AF patients who developed RAO, the risk of thromboembolic complications is almost $40 \%$ higher than in AF patients in whom an episode of RAO did not occur [7]. In addition, patients who have already been diagnosed with AF who develop RAO may require initiation or modification of anticoagulant treatment, the selection of which is based on stratification of thromboembolic risk based on the $\mathrm{CHA}_{2} \mathrm{DS}_{2}$-VASc score (Table 1) [1, 4, 7, 9]. As most cardiogenic strokes and their recurrences can be prevented by appropriate preventive treatment, an early diagnosis of stroke aetiology, including RAO, is important.

This research presents a review of literature, the aim of which is to analyse the relationship between AF and RAO.

\section{Atrial fibrillation as one of the causes of RAO}

Embolism of cardiac origin is the second most common aetiology of RAO after carotid atherosclerosis [4, 8, 18-20]. The most common cardiac causes of RAO, include the presence of degenerative changes on the cusps of the aortic and mitral valve. Calcifications at the edges or the base of the cusps, valvular stenosis and regurgitation are reported most $[8,21]$. Other causes of embolism of cardiac origin include the presence of aortic atherosclerotic plaques, bacterial vegetations, intracardiac thrombi and tumours, or the presence of a patent foramen ovale (PFO) [22-25]. 
Cardiac arrhythmias are also one of the causes of cardiac embolism. AF is one of the most common arrhythmias diagnosed in patients with RAO [7, 14-16, 20, 26-30].

In the available studies that addressed the aetiology of RAO, AF was considered separately or classified as an arrhythmia or a cardiovascular cause of RAO, where the percentage of AF itself was no longer considered, resulting in significant discrepancies in the presented results [20, 21, 26-30].

Schmidt et al. observed cardiac arrhythmia in $16 \%$ of patients, but there is no information on the percentage of AF [21]. In the study by Hong et al., AF and valvular heart disease were included together, and their combined prevalence in RAO patients was 6\% [26]. Similarly, in the study by Kim et al. valvular heart disease or AF were included together, but the result was much higher, $17 \%$ of RAO patients were diagnosed with valvular heart disease or AF [20]. In the study by Callizo et al. [27], arrhythmia is mentioned, without determine its type. In this study, cardiac arrhythmias were observed in $20 \%$ of patients with CRAO. In a study by Lavin et al. [28], 10.6\% of patients had a history of AF or were diagnosed with AF at the time of CRAO diagnosis. A much lower percentage of $A F$ is reported in the study by Laczynski et al. [29], where AF was present in $1.8 \%$ of RAO patients. Rim et al. [30] in the RAO group, AF was diagnosed in $9 \%$ of cases. It is important that in this study AF occurred statistically significantly more often in the RAO group than in the group of patients who did not suffer from an episode of RAO $(9 \%$ vs. $4.3 \%, p<0.001$ ) [30].

When analysing the relationship between $\mathrm{RAO}$ and $\mathrm{AF}$, it is worth noting that many cardiovascular risk factors found in RAO patients are also risk factors [8, 21, 27, 31]. Both AF and RAO mainly affect the elderly. It is well known that both the incidence and prevalence of $A F$ increase rapidly with age, especially after the age of 65 [3, 32]. In most studies, the mean age of RAO patients exceeds 60 years [ 6 , $8,16-19,26-30]$. Among patients over 85 years of age, the percentage of patients with AF increases to as much as $17.8 \%$. We are now observing an ageing population. It is estimated that the number of patients with AF will increase 2.5 times by 2050 [1]. Ageing and age-related underlying diseases cause myocardial remodelling that can lead to cardiac electrical abnormalities that increase the incidence or persistence of AF [32]. The elderly, including patients with RAO, more frequently suffer from conditions that predispose them to arrhythmias, such as hypertension, diabetes, ischemic heart disease, heart failure, and valvular defects. In the study by Callizo et al. [27], the proportion of cardiovascular risk factors that remained undiagnosed until the occurrence of an RAO episode was estimated at the level of $78 \%$. Hypertension is the most observed risk factor for patients with RAO, patients with a history of stroke, and patients with $\operatorname{AF}[1,6,8,21,27,33-35]$. The prevalence of hypertension makes it a much more common contributor to the development of AF than any other risk factor. The risk of developing $A F$ is, respectively, 1.4 and 1.5 times higher in men and women with hypertension [33]. It is worth noting that AF also exacerbates biological ageing, particularly at the level of the brain, which stems from the fact that AF-related ischaemic incidents that impair functional capacity [32].

Although AF is observed in RAO patients, the question of whether AF can be an independent cause of RAO has raised some doubts $[30,35]$. The main cause of embolism in patients with $\mathrm{AF}$ are thrombi released from the left atrial appendage [1]. In a study by Mead et al. [35], however, the authors indicate that thrombi that form in the atria may be too large to cause RAO, in contrast to smaller thrombi that form on an atherosclerotic plaque in the carotid artery. Due to high blood velocities at the site of carotid artery stenosis thrombi are displaced from the surface of the atherosclerotic plaque at an early stage of their formation, when they are small, whereas thrombi developing in environments where blood velocity is low, in the atria, may grow larger before they move into the aorta. Large thrombi passing through the internal carotid artery will most likely remain inside the stream and it is unlikely to enter the ophthalmic artery that branches off at a sharp angle. Smaller thrombi can drift in the periphery of the bloodstream and thus enter the ophthalmic artery more easily. Small embolic material may cause ocular symptoms; after entering the cerebral circulation, it may not produce any clinical symptoms at all [35].

In the case of RAO patients, recent studies using diffusion-weighted imaging magnetic resonance (DWI-MR), performed within 7 days after the occurrence of RAO, reveal a high percentage of acute ischemic lesions, most of which are not accompanied by clinical symptoms $[18,19]$. Studies show that ischemic lesions observed in DWI-MR in RAO patients are associated with a greater likelihood of detecting the aetiology of RAO. In these studies, the most identified aetiology of RAO were carotid atherosclerosis, followed by cardioembolism $[18,19]$. However, the high proportion of patients with undetermined aetiology of RAO is noteworthy $[19,20]$. Cardiogenic embolism in the setting of asymptomatic arrhythmias or undiagnosed cardiac defects is thought to be responsible for most cryptogenic strokes. The likelihood of diagnosing paroxysmal AF in a patient with a stroke of unclear aetiology is greater when the imaging reveals multiple cerebral vascular lesions [odds ratio (OR) 1.7] or an ischaemic focus involving the cerebral cortex or cerebellum (OR 5.8) [36]. Lauda et al. hypothesise that the high proportion of patients with undetermined aetiology of monocular ischaemic visual loss, including RAO, in their study, is associated with undiagnosed AF [19].

In AF patients, similarly to patients with RAO, it is observed the presence of silent brain infarcts (SBI) [2, 18-20]. 
A synergistic effect of micro thrombosis and haemodynamic abnormalities is believed to be one of the mechanisms that may lead to $\mathrm{SBI}$ in AF patients. According to researchers, left atrial abnormalities and atherosclerotic plaques of the carotid arteries and aortic arch may play an important role in the development of SBI. In some studies, spontaneous contrast of blood on echocardiography was identified as a risk factor of thromboembolic events. Fibrinogen-mediated erythrocyte aggregation and microembolization by small thrombi forming in the fibrillating left atrial appendage are possible mechanisms of an increased risk of thromboembolic events [2]. It can be assumed that the same mechanisms in AF patients can lead not only to SBI but also to RAO. Wijman et al. [37] presented a description of two cases where recently diagnosed AF may have been responsible for the occurrence of an episode of RAO. The authors of the study speculate that the embolism was caused by the detachment of a thrombus fragment that originally moved from the atrium to the internal carotid artery. Based on a study involving a group of patients with retinal vascular occlusion without a history of an AF episode, Christansen et al. [9] observed that AF was diagnosed statistically significantly more often in patients with a history of RAO than in patients without a history of RAO, which may suggest that the presence of arrhythmia was the cause of the RAO episode.

\section{Cardiological diagnostic evaluation of patients with RAO}

Recent studies indicate that the incidence of $\mathrm{AF}$ in RAO patients may be underestimated [10, 12, 19]. According to the authors, it may stem from the fact that these patients are monitored for a period that is not sufficiently long. Most patients with RAO undergo diagnostic imaging of the carotid arteries and echocardiography, but the evaluation of cardiac rhythm in these patients is mostly limited to 12-lead resting electrocardiography [12]. Zarkala et al. [12] evaluated 400 patients with transient or permanent monocular ischaemic vision loss. ECGs were performed in 364 patients (91\%), but only 211 (53\%) underwent prolonged electrocardiographic monitoring. In the vast majority (97.3\%) carotid artery imaging was performed. Thirty-six patients (9\%) were diagnosed with AF, and 53 (14\%) had ipsilateral carotid artery stenosis. The authors indicate that the results may be underestimated as only $53 \%$ of patients underwent prolonged electrocardiographic monitoring [12]. Christiansen et al. [7] also emphasise that patients with retinal vascular occlusion may require prolonged electrocardiographic monitoring to detect underlying (often asymptomatic) AF, as a "single" 12-lead electrocardiogram may not suffice [7].

It should be remembered that thromboembolic risk is similar in the case of paroxysmal and persistent AF; even
Table 2. Clinical risk assessment scale that measures the risk of paroxysmal atrial fibrillation in patients with cryptogenic stroke [36]

$\begin{array}{lc}\text { Risk factor } & \text { Score } \\ \text { Age }>62 & 2 \\ \text { NIHSS } \geq 8 \text { points } & 1 \\ \text { Left atrial enlargement } & 2 \\ \text { Exclusion of vascular pathology* } & 3 \\ \text { Score } \geq 5 \text { points - sensitivity } 89 \%, \\ \text { specificity } 88 \% \text { for paroxysmal AF } \\ \text { *Stenosis of } \geq 50 \% \text { of intracerebral or intracranial arteries, arterial dissection, clinico-radiological } \\ \text { signs of lacunar stroke; NIHSS - National Institutes of Health Stroke Scale }\end{array}$

brief episodes that last a few minutes are associated with a higher incidence of ischaemic events [1, 31]. Since paroxysmal AF is difficult to diagnose because episodes are often brief, oligosymptomatic or accompanied by nonspecific symptoms, continuous monitoring is preferred when conducting a diagnostic evaluation for paroxysmal/subclinical $\operatorname{AF}[31,36]$. In patients hospitalised due to ischaemic stroke, the detection rate of paroxysmal AF based on ECG alone is low - 2-4\%. Therefore, ECG monitoring plays a very important role in the diagnostic evaluation: Holter monitoring during hospitalisation for 24 hours and repeated outpatient Holter monitoring for 7-14 days. The use of 30-day ECG monitoring in patients who suffered a cryptogenic stroke increases the chance of diagnosing AF by five times compared to standard 24-hour Holter ECG (16\% vs. 3.2\%) [36]. There are clinical scales that help identify cryptogenic stroke patients in whom the risk of paroxysmal AF is high (Table 2) [36].

As shown in the studies by Callizo et al. [10] and Lavin et al. [28], the longer the duration of the monitoring using Holter ECG, the greater the chance of identifying the arrhythmia that may be the cause of RAO. In the study by Callizo et al. [10], the use of 7-day Holter monitoring increased the proportion of patients with RAO and AF from 12 to $16 \%$. In the study by Lavin et al. [28], the use of 30-days-long Holter ECG monitoring made it possible to detect AF in $8.8 \%$ of subjects.

In the study by Callizo et al. [10], there was no statistically significant difference in the incidence of AF between RAO patients and ischaemic stroke patients. In contrast to the results of this study, a study by Schorr et al. [16] revealed that $A F$ was statistically significantly more often diagnosed in patients with ischaemic stroke than in RAO patients. Even though the incidence of AF was lower in RAO patients compared to patients with ischaemic stroke, patients with RAO were more than twice as often re-hospitalized for atrial arrhythmia/fibrillation, further emphasizing the need for prolonged monitoring of this patient group [16].

The percentage of diagnosed arrhythmias increases in patients in whom implantable loop recorders or event recorders were applied. The Crystal-AF (Study of Continuous 
Cardiac Monitoring to Assess Atrial Fibrillation After Cryptogenic Stroke) study revealed that patients who suffered a cryptogenic stroke, in whom AF was not diagnosed based on the routine diagnostic evaluation, the implantable recorder made it possible to diagnose paroxysmal AF within 6 months in $8.9 \%$ of patients, and within 12 months in $12.4 \%$ of patients, compared to $1.4 \%$ and $2.0 \%$, respectively, in the control group that received the routine, 24-hour Holter monitoring [38].

In a study by Mac Grory et al. [15], implantable event recorders applied in patients after CRAO also revealed a high percentage of AF patients. Within 3 months, AF was diagnosed in $7.7 \%$ of patients and after 36 months - in $33.3 \%$ of patients.

Watson et al. [13] used implantable event recorders to evaluate the risk of subclinical AF in patients with CRAO, compared to patients with cryptogenic stroke. The study revealed that the incidence of subclinical AF in CRAO patients was similar to that observed in the cryptogenic stroke group. Predictors of AF included older age, a higher $\mathrm{CHA}_{2} \mathrm{DS}_{2}$-VASc score, longer PR interval in the first ECG, and presence of calcifications on the mitral valve annulus visualized by transthoracic echocardiography [13].

In the diagnostic evaluation of cardiac causes of embolism, both transthoracic and, in selected cases, transoesophageal echocardiography is indispensable. Transoesophageal echocardiography makes it possible to conduct a better examination of the valves, intracardiac leaks, including PFO, and the presence of thrombi [39].

When assessing thromboembolic risk in echocardiography, attention should be paid to left ventricular systolic dysfunction, atherosclerotic changes in the aorta, left atrial enlargement, the presence of thrombi and spontaneous contrast in the left atrium, as well as decreased left atrial appendage emptying velocity (Table 3) [36].

Table 3. Echocardiographic predictors of a high risk of thromboembolic events in patients with atrial fibrillation [36]

\begin{tabular}{lc}
\hline Risk factors & Study \\
\hline $\begin{array}{l}\text { Left ventricular systolic dysfunction (LVEF < 35\%) } \\
\text { Atherosclerotic lesions in the ascending aorta }\end{array}$ & TTE \\
$\begin{array}{l}\text { Presence of a thrombus in the left atrial } \\
\text { appendage }\end{array}$ & TEE \\
$\begin{array}{l}\text { Presence of spontaneous contrast in the left atrial } \\
\text { appendage }\end{array}$ & TEE \\
$\begin{array}{l}\text { Signs of left atrial appendage dysfunction (decreased } \\
\text { flow velocity } \leq 20 \mathrm{~cm} / \mathrm{s} \text { and/or impaired systolic }\end{array}$ & TEE \\
function of the left atrial appendage) & Or \\
$\begin{array}{l}\text { Left atrial enlargement } \\
\text { LVEF - left ventricular ejection fraction; } \text { TE - transthoracic echocardiography; TEE - transoeso- } \\
\text { phageal echocardiography }\end{array}$ & TTE \\
\end{tabular}

Echocardiography should also look for features of atrial cardiomyopathy, during which the left atrium undergoes unfavourable remodelling, with enlargement, fibrosis, and malfunction, which may be the cause of thrombus formation in the left atrium, regardless of the presence of $\mathrm{AF}$ itself [40].

As a result of improved diagnostic tools and advances in diagnosing $A F$, the number of strokes and RAO without an identifiable cause decreases, which enables early implementation of secondary prevention aimed at reducing the risk of subsequent thromboembolic incidents.

\section{Risk of stroke in a patient with RAO and AF}

RAO patients have a statistically significantly higher risk of stroke than patients who did not suffer an episode thereof. Studies show that the risk is the highest during the month following the occurrence of RAO, especially in the first week $[4,6,17,18,30]$.

The risk of stroke was also higher in patients with both AF and RAO than in patients with AF who did not suffer an episode of RAO. Christiansen et al. conducted a retrospective evaluation of patients from the AF registry from the years 1997-2008. This registry included 87,202 patients with nonvalvular AF, 224 (0.26\%) of whom were diagnosed with RAO. In patients with AF who were diagnosed with RAO, the risk of thromboembolic events - i.e., ischaemic stroke, transient cerebral ischaemia, or peripheral embolism - was approximately $40 \%$ greater than in those without RAO [7]. The impact of RAO on an increased risk of stroke in patients with AF is of particular importance due to the stratification of the risk of thromboembolic episodes, which constitutes the basis for decisions concerning the anticoagulation treatment in AF patients. According to guidelines, the $\mathrm{CHA}_{2} \mathrm{DS}_{2}$-VASc score, based on a point system (Table 1 ), is recommended for the stratification of the thromboembolic risk [1, 31]. The risk, estimated following the $\mathrm{CHA}_{2} \mathrm{DS}_{2}-\mathrm{VASc}$ score, can reach a maximum of 9 points. The risk of thromboembolic complications secondary to $\mathrm{AF}$ is high when a man scores 2 or more on the scale and a woman scores 3 or more [1, 31].

Christiansen et al. suggested that RAO episodes should be included in the $\mathrm{CHA}_{2} \mathrm{DS}_{2}$-VASc score, as a component of vascular disease [7]. Currently, RAO is viewed as an equivalent of stroke $[4,5]$, and in this view, a patient who suffered an episode of RAO should receive 2 points, which means that he or she is at a high risk of thromboembolic complications, implying the need for appropriate anticoagulant treatment in patients with AF. Effective treatment with oral anticoagulants can reduce the incidence of strokes in $\mathrm{AF}$ by up to $80 \%$ [2]. 


\section{Summary}

The relationship between the occurrence of RAO and the risk of stroke, especially in the period immediately after RAO, obliges ophthalmologists to extend diagnostic evaluation, including the diagnostic evaluation for the presence of AF. Cardiologists evaluating AF patients in respect of thromboembolic risk stratification should remember to consider a possible episode of RAO that the patient may have undergone in the past. According to the $\mathrm{CHA}_{2} \mathrm{DS}_{2}$-VASC score, RAO that is equivalent of stroke should receive 2 points during the stratification of the risk of subsequent thromboembolic episodes.

\section{Conflict of interest}

The authors report no conflicts of interest.

\section{References}

1. Wożakowska-Kapłon B, Gorczyca-Michta I, Filipiak K, et al. Prewencja powikłań zakrzepowo-zatorowych $u$ chorych z migotaniem przedsionków - propozycja algorytmu dla lekarzy rodzinnych. Forum Med Rodz. 2013; 7(1): 1-15.

2. Hahne K, Mönnig G, Samol A. Atrial fibrillation and silent stroke: links, risks, and challenges. Vasc Health Risk Manag. 2016; 12: 65-74, doi: 10.2147/VHRM.S81807, indexed in Pubmed: 27022272.

3. Wolf PA, Abbott RD, Kannel WB. Atrial fibrillation as an independent risk factor for stroke: the Framingham Study. Stroke. 1991; 22(8): 983-988, doi: 10.1161/01.str.22.8.983, indexed in Pubmed: 1866765.

4. Biousse V, Nahab F, Newman NJ. Management of acute retinal ischemia: follow the guidelines! Ophthalmology. 2018; 125(10): $1597-$ -1607, doi: 10.1016/j.ophtha.2018.03.054, indexed in Pubmed: 29716787.

5. Sacco RL, Kasner S, Broderick J, et al. An updated definition of stroke for the 21st century. Stroke. 2013; 44(7): 2064-2089, doi: 10.1161/ /str.0b013e318296aeca.

6. Chang YS, Jan RL, Weng SF, et al. Retinal artery occlusion and the 3-year risk of stroke in Taiwan: a nationwide population-based study. Am J Ophthalmol. 2012; 154(4): 645-652.e1, doi: 10.1016/j. ajo.2012.03.046, indexed in Pubmed: 22809785.

7. Christiansen $\mathrm{CB}$, Torp-Pedersen C, Olesen JB, et al. Retinal vein and artery occlusions: a risk factor for stroke in atrial fibrillation. J Thromb Haemost. 2013; 11(8): 1485-1492, doi: 10.1111/jth.12297, indexed in Pubmed: 23663383.

8. Hayreh SS, Podhajsky PA, Zimmerman MB. Retinal artery occlusion: associated systemic and ophthalmic abnormalities. Ophthalmology. 2009; 116(10): 1928-1936, doi: 10.1016/j.ophtha.2009.03.006, indexed in Pubmed: 19577305.

9. Christiansen CB, Torp-Pedersen C, Olesen JB, et al. Risk of incident atrial fibrillation in patients presenting with retinal artery or vein occlusion: a nationwide cohort study. BMC Cardiovasc Disord. 2018; 18(1): 91, doi: 10.1186/s12872-018-0825-1, indexed in Pubmed: 29743025.

10. Callizo J, Feltgen $\mathrm{N}$, Ammermann A, et al. Atrial fibrillation in retinal vascular occlusion disease and non-arteritic anterior ischemic optic neuropathy. PLoS One. 2017; 12(8): e0181766, doi: 10.1371/journal. pone.0181766, indexed in Pubmed: 28771491.
11. Yen JC, Lin HL, Hsu CA, et al. Atrial fibrillation and coronary artery disease as risk factors of retinal artery occlusion: a nationwide population-based study. Biomed Res Int. 2015; 2015: 374616, doi: 10.1155/2015/374616, indexed in Pubmed: 26558268.

12. Zarkali A, Cheng SF, Dados A, et al. Atrial fibrillation: an underestimated cause of ischemic monocular visual loss? J Stroke Cerebrovasc Dis. 2019; 28(6): 1495-1499, doi: 10.1016/j.jstrokecerebrovasdis.2019.03.017, indexed in Pubmed: 30935808.

13. Watson RA, Wellings J, Hingorani R, et al. Atrial fibrillation post central retinal artery occlusion: role of implantable loop recorders. Pacing Clin Electrophysiol. 2020; 43(9): 992-999, doi: 10.1111/pace.13990, indexed in Pubmed: 32567072.

14. Meyer-Zurn CS, Haertig F, Weyland C, et al. Detection of paroxysmal atrial fibrillation in patients with central retinal artery occlusion by insertable loop recorders. Eur Heart J. 2017; 38(Suppl_1): 885, doi: 10.1093/eurheartj/ehx504.p4314.

15. Mac Grory B, Ziegler P, Landman S, et al. Detection of atrial fibrillation by implantable cardiac monitoring after acute central retinal artery occlusion. Stroke. 2020; 1(Suppl_1): A23.

16. Schorr EM, Rossi KC, Stein LK, et al. Characteristics and outcomes of retinal artery occlusion: nationally representative data. Stroke. 2020; 51(3): 800-807, doi: 10.1161/STROKEAHA.119.027034, indexed in Pubmed: 31951154.

17. Park SJ, Choi NK, Yang BoR, et al. Risk and risk periods for stroke and acute myocardial infarction in patients with central retinal artery occlusion. Ophthalmology. 2015; 122(11): 2336-2343.e2, doi: 10.1016/j.ophtha.2015.07.018, indexed in Pubmed: 26298716.

18. Lee J, Kim SW, Lee SC, et al. Co-occurrence of acute retinal artery occlusion and acute ischemic stroke: diffusion-weighted magnetic resonance imaging study. Am J Ophthalmol. 2014; 157(6): 1231-1238, doi: 10.1016/j.ajo.2014.01.033, indexed in Pubmed: 24503410.

19. Lauda F, Neugebauer H, Reiber L, et al. Acute silent brain infarction in monocular visual loss of ischemic origin. Cerebrovasc Dis. 2015: 40(3-4): 151-156, doi: 10.1159/000437274, indexed in Pubmed: 26278894.

20. Kim YD, Kim JY, Park YJ, et al. Cerebral magnetic resonance imaging of coincidental infarction and small vessel disease in retinal artery occlusion. Sci Rep. 2021; 11(1): 864, doi: 10.1038/s41598-02080014-9, indexed in Pubmed: 33441709.

21. Schmidt D, Hetzel A, Geibel-Zehender A, et al. Systemic diseases in non-inflammatory branch and central retinal artery occlusion - an overview of 416 patients. Eur J Med Res. 2007; 12(12): 595-603, indexed in Pubmed: 18024271.

22. Mouradian M, Wijman CAC, Tomasian D, et al. Echocardiographic findings of patients with retinal ischemia or embolism. J Neuroimaging. 2002; 12(3): 219-223, indexed in Pubmed: 12116739.

23. Leisser $\mathrm{C}$, Kaufmann TA, Feltgen $\mathrm{N}$, et al. Distribution of internal carotid artery plaque locations among patients with central retinal artery occlusion in the Eagle study population. Graefes Arch Clin Exp Ophthalmol. 2015; 253(8): 1227-1230, doi: 10.1007/s00417-0142804-2, indexed in Pubmed: 25500982.

24. Schmidt D, Hetzel A, Geibel-Zehender A. Retinal arterial occlusion due to embolism of suspected cardiac tumors - report on two patients and review of the topic. Eur J Med Res. 2005; 10(7): 296-304, indexed in Pubmed: 16055401.

25. Shoeibi N, Poorzand H, Abrishami M. Branch retinal artery occlusion in a patient with patent foramen ovale. J Ophthalmic Vis Res. 2013; 8(1): 58-61, indexed in Pubmed: 23825714. 
26. Hong JH, Sohn SI, Kwak J, et al. Retinal artery occlusion and associated recurrent vascular risk with underlying etiologies. PLoS One. 2017; 12(6): e0177663, doi: 10.1371/journal.pone.0177663, indexed in Pubmed: 28570629.

27. Callizo J, Feltgen N, Pantenburg S, et al. European Assessment Group for Lysis in the Eye. Cardiovascular risk factors in central retinal artery occlusion: results of a prospective and standardized medical examination. Ophthalmology. 2015; 122(9): 1881-1888, doi: 10.1016/j. ophtha.2015.05.044, indexed in Pubmed: 26231133.

28. Lavin P, Patrylo M, Hollar M, et al. Current treatment of central retinal artery occlusion: a national survey. J Neurol. 2018; 265(2): 330-335, doi: 10.1007/s00415-017-8702-x, indexed in Pubmed: 29236169.

29. Laczynski DJ, Gallop J, Lyden SP, et al. Retinal artery occlusion does not portend an increased risk of stroke. J Vasc Surg. 2020; 72(1): 198-203, doi: 10.1016/j.jvs.2019.08.279, indexed in Pubmed: 31843299.

30. Rim TH, Han J, Choi YS, et al. Retinal artery occlusion and the risk of stroke development: twelve-year nationwide cohort study. Stroke. 2016; 47(2): 376-382, doi: 10.1161/STROKEAHA.115.010828, indexed in Pubmed: 26742801.

31. Hindricks G, Potpara T, Dagres N, et al. ESC Scientific Document Group. 2020 ESC Guidelines for the diagnosis and management of atrial fibrillation developed in collaboration with the European Association for Cardio-Thoracic Surgery (EACTS): The Task Force for the diagnosis and management of atrial fibrillation of the European Society of Cardiology (ESC) Developed with the special contribution of the European Heart Rhythm Association (EHRA) of the ESC. Eur Heart J. 2021; 42(5): 373-498, doi: 10.1093/eurheartj/ehaa612, indexed in Pubmed: 32860505.
32. Ravassa S, Ballesteros G, Díez J. Aging and atrial fibrillation: a matter of fibrosis. Aging (Albany NY). 2019; 11(22): 9965-9966, doi: 10.18632/aging.102501, indexed in Pubmed: 31754085.

33. Kjeldsen SE, Tonje TA, Schmieder RE. Nadciśnienie tętnicze i migotanie przedsionków - profilaktyka. Choroby Serca i Naczyń. 2009; 6(3): 109-113.

34. O'Donnell MJ, Xavier D, Liu L, et al. Risk factors for ischaemic and intracerebral haemorrhagic stroke in 22 countries (the INTERSTROKE study): a case-control study. The Lancet. 2010; 376(9735): 112-123, doi: 10.1016/s0140-6736(10)60834-3.

35. Mead GE, Lewis S, Wardlaw J, et al. Comparison of risk factors in patients with transient and prolonged eye and brain ischemic syndromes. Stroke. 2002; 33(10): 2383-2390, doi: 10.1161/01. str.0000029827.93497.97.

36. Staszewski J, Pruszczyk P, Diagnostyka udaru kardiogennego. Neurologia po Dyplomie 05/2015. https://www.podyplomie.pl/neurologia/ /19037, diagnostyka-udaru-kardiogennego (October 19, 2021).

37. Wijman CA, Babikian VL, Kappelle J. Retinal ischemia in atrial fibrillation: do not overlook the carotid artery. https://dspace.library.uu.nl/ /bitstream/1874/21529/7/full.pdf (October 19, 2021).

38. Sanna T, Diener HC, Passman RS, et al. CRYSTAL AF Investigators. Cryptogenic stroke and underlying atrial fibrillation. $\mathrm{N}$ Engl J Med. 2014; 370(26): 2478-2486, doi: 10.1056/NEJMoa1313600, indexed in Pubmed: 24963567.

39. Roskal-Wałek J, Wałek P, Sielski J, et al. Zator tętnicy siatkówki objawem chorób sercowo-naczyniowych. Okulistyka. 2016; 2: 22-26.

40. Kamel H, Okin PM, Longstreth WT, et al. Atrial cardiopathy: a broadened concept of left atrial thromboembolism beyond atrial fibrillation. Future Cardiol. 2015; 11(3): 323-331, doi: 10.2217/fca.15.22, indexed in Pubmed: 26021638. 